\title{
Schizophrenia - Insight, Depression: A correlation study
}

\author{
Ananda Reddy Endreddy ${ }^{1}$, Subahani Shaik², Bhagawan Rajana ${ }^{3}$ \\ ${ }^{1}$ Dr Ananda Reddy Endreddy, ${ }^{2}$ Dr Subahani Shaik, ${ }^{3}$ Dr Bhagawan Rajana, all authors are affiliated with Departments of \\ Psychiatry, Narayana Medical College and Hospital, Nellore, Andhra Pradesh, India.
}

Address for Correspondence: Dr. Ananda Reddy Endreddy, Associate Professor, Department of Psychiatry, Narayana Medical College and Hospital, Nellore, Andhra Pradesh, India. E-mail: anandendreddy@gmail.com

\begin{abstract}
Background: Schizophrenia is one of the severe forms of mental illness which demands enormous personal and economical costs. Recent years have attracted considerable interest in the dual problem of depression in schizophrenia and its relation to insight. Most clinicians believe that poor insight in patients with schizophrenia, though problematic for treatment adherence, may be protective with respect to suicide. Aims and objectives: Our study was aimed to find out the correlation between insight and depression in schizophrenic population. Materials and Methods: Present study was a cross sectional, single centred, correlation study done in total of 60 subjects. Subjects aged between 20 to 60 years, diagnosed to have schizophrenia as per ICD-10 and who have given written consent been considered for the study. Subjects who had other psychiatric disorders such as mood disorder, schizoaffective disorder, mental retardation, epilepsy or detectable organic disease and co morbid substance abuse were excluded from the study. Schizophrenics with acute exacerbation were also excluded from the study. For insight assessment, schedule for assessment of insight (SAI), a three item rating scale was used. For the assessment of depressive symptoms, a nine item rating scale, Calgary Depression Rating Scale (CDRS) was administrated. Results: Insight and depression were strongly correlated in schizophrenic population with a Pearson correlation coefficient of 0.758 . The correlation between insight and depression was high in subjects with less duration of illness. Conclusions: Our study suggests that poor insight may protect against depression in the early stages of recovery from schizophrenia. The correlation between insight and depression was high in subjects with less duration of illness.
\end{abstract}

Keywords: Depression, Insight, Schizophrenia

\section{Introduction}

Schizophrenia is one of the severe forms of mental illness which demands enormous personal and economical costs. Globally it is estimated that 25 million people have schizophrenia [1]. Recent years have attracted considerable interest in the dual problem of depression in schizophrenia and its relation to insight. Among the primary dimensions of insight, the following were included: 1) the awareness of having an illness, its signs and symptoms. The awareness and attribution of recognizable symptoms to that illness, the temporal projection of the insight, distinguishing between actual or retrospective insight, and assuming that insight may vary in different stages of the psychotic process [2,3]. Semrad and Eissler, however, had seen

Manuscript received $25^{\text {th }}$ September 2016

Reviewed: $6^{\text {th }}$ October 2016

Author Corrected: $16^{\text {th }}$ October 2016

Accepted for Publication $31^{\text {st }}$ October 2016 depression in schizophrenia as a moment of therapeutic opportunity, when insight and mastery might overcome more primitive defensive psychotic ego states as they receded [4]. Between $50 \%$ and $80 \%$ of the patients diagnosed with schizophrenia have been shown to be partially or totally lacking insight into the presence of their mental disorder.

Although a causal chain connecting poor insight with poor treatment adherence and thus with poorer outcome and functioning is straight forward, numerous studies investigating correlates and long-term impact of insight have provided differing results. In addition, higher levels of insight in schizophrenia have been associated with depression and hopelessness, but the causal direction of the relationship was unclear and the data were inconclusive [5]. Schizophrenia is a highly 
stigmatising disorder and many individuals with this diagnosis feel devalued and discriminated [6]. Societal, and sometimes medical views include the belief that it is a chronic, debilitating condition from which individuals have little chance of recovering [7]. This conceptualisation can be threatening and distressing to those given the diagnosis, and is likely to contribute to the high level of depression experienced by many people with schizophrenia [8]. Indeed, a number of cross-sectional studies support a relationship between higher insight and greater distress, including depression, [9] hopelessness, [10] and suicidality [11].

Most clinicians believe that poor insight in patients with schizophrenia, though problematic for treatment adherence, may be protective with respect to suicide. The assumption is that patients who do not believe that they are ill are less likely to be suicidal. Alternatively, those patients with schizophrenia who recognize and acknowledge the illness will be more suicidal [12]. As per Moore et al, patients with a greater unawareness of their illness had relatively less depressive symptomotology and relatively greater self deception.

This relationship was particularly strong for unawareness of the social consequences of a mental disorder. These results suggest that the presence of depressive symptomotology in schizophrenia is related to insight [13].

\section{Results}

Distribution of sample based on gender, marital status, and educational status was shown in table 1 to table 3 . Both the insight and depression were more in male population with schizophrenia when compared to females. Married patients have lesser insight and lesser depressive ideas than the unmarried patients. Results were suggestive of higher insight and higher depression in literates when compared to illiterates. Both insight and depression were low among schizophrenic patients with age above 40 years when compared to the patients aged below 30 years. (table4)

Distribution of sample based on the duration of illness was shown in table 5. Both insight and depression were low among schizophrenic patients with duration of illness more than 5 years. Insight and depression were high among schizophrenic patients with duration of illness less than 2 years. The correlation between insight and depression in overall sample was shown table 6. The Pearson correlation coefficient is 0.758 and is suggesting strong correlation between both variables. It is significant at 0.01 levels ( $p$ value).

Table-1: Distribution of sample based on gender Dimension.

\begin{tabular}{|c|c|c|c|c|c|c|}
\hline Dimension & Variable & n & Mean of sample & Sd & t & P \\
\hline \multirow{2}{*}{ Insight } & Male & 28 & 6.46 & 4.359 & 0.468 & 0.642 \\
\cline { 2 - 6 } & Female & 32 & 5.94 & 4.347 & & 0.668 \\
\hline \multirow{2}{*}{ Depression } & Male & 28 & 9.38 & 6.311 & 0.507 \\
\cline { 2 - 5 } & Female & 32 & 8.25 & 6.733 & & \\
\hline
\end{tabular}

Both the insight and depression were more in male population with schizophrenia when compared to females. 
Table-2: Distribution of sample based on Marital Status.

\begin{tabular}{|c|c|c|c|c|c|c|}
\hline Dimension & Variable & $\mathbf{n}$ & Mean & Sd & t & P \\
\hline \multirow{2}{*}{ Insight } & Male & 28 & 9.73 & 3.312 & \multirow{2}{*}{6.221} & \\
\cline { 2 - 5 } & Female & 32 & 4.13 & 3.434 & & 0.001 \\
\hline \multirow{2}{*}{ depression } & Male & 28 & 13.45 & 5.894 & 4.779 & 0.001 \\
\cline { 2 - 5 } & Female & 32 & 6.18 & 5.286 & & \\
\hline
\end{tabular}

Married patients have lesser insight and lesser depressive ideas than the unmarried patients.

Table-3: Distribution of sample based on Literacy.

\begin{tabular}{|c|c|c|c|c|c|c|}
\hline Dimension & Variable & n & Mean & Sd & t & P \\
\hline Insight & Literate & 28 & 9.32 & 3.400 & 6.221 & 0.001 \\
\hline & illeterate & 32 & 3.44 & 2.972 & & 0.001 \\
\hline depression & literate & 28 & 13.32 & 5.320 & 4.779 & \\
\hline
\end{tabular}

Results were suggestive of higher insight and higher depression in literates when compared to illiterates

Table-4: Distribution of sample based on age.

\begin{tabular}{|c|c|c|c|c|c|c|}
\hline Dimension & variable & $\mathbf{n}$ & Mean & SD & $\mathbf{t}$ & $\mathbf{p}$ \\
\hline \multirow[t]{3}{*}{ Insight } & below30 & 17 & 10.1 & 2.938 & \multirow{3}{*}{24.451} & \multirow{3}{*}{0.001} \\
\hline & $30-40$ & 21 & 3.44 & 2.972 & & \\
\hline & above 40 & 22 & 13.32 & 5.320 & & \\
\hline \multirow[t]{3}{*}{ depression } & below30 & 17 & 4.94 & 4.704 & \multirow{3}{*}{17.392} & \multirow{3}{*}{0.001} \\
\hline & $30-40$ & 21 & 7.52 & 5.750 & & \\
\hline & above 40 & 22 & 3.56 & 4.786 & & \\
\hline
\end{tabular}

Both insight and depression were low among schizophrenic patients with age above 40 years when compared to the patients aged below 30 years

Table-5: Distribution of sample based on Duration of schizophrenic illness

\begin{tabular}{|c|c|c|c|c|c|c|}
\hline Dimension & variable & $\mathrm{n}$ & Mean & SD & $\mathrm{t}$ & $\mathrm{p}$ \\
\hline \multirow{3}{*}{ Insight } & $<2 y r s$ & 24 & 9.96 & 2.881 & \multirow{3}{*}{36.065} & \multirow{3}{*}{0.001} \\
\hline & $2-5 y r s$ & 19 & 4.74 & 3.194 & & \\
\hline & $>5 y r s$ & 17 & 2.47 & 2.649 & & \\
\hline \multirow{3}{*}{ depression } & $<2 \mathrm{yrs}$ & 24 & 15.17 & 3.608 & \multirow{3}{*}{51.501} & \multirow{3}{*}{0.001} \\
\hline & $2-5 y r s$ & 19 & 5.21 & 4.404 & & \\
\hline & $>5 y r s$ & 17 & 4.00 & 3.889 & & \\
\hline
\end{tabular}

Distribution of sample based on the duration of illness was shown in table 5. Both insight and depression were low among schizophrenic patients with duration of illness more than 5 years. Insight and depression were high among schizophrenic patients with duration of illness less than 2 years.

Table-6: Correlation between Insight and Depression in overall sample

\begin{tabular}{|c|c|}
\hline Variables & Depression \\
\hline Insight & $0.758 * *$ \\
\hline
\end{tabular}

** Correlation is significant at the 0.01 level. 
The correlation between insight and depression in overall sample was shown table 6 . The Pearson correlation coefficient is 0.758 and is suggesting strong correlation between both variables. It is significant at 0.01 levels ( $p$ value).

Table-7: Correlation between Insight and Depression with all variables.

\begin{tabular}{|c|c|c|c|c|c|}
\hline \multicolumn{2}{|l|}{ Variable } & \multirow{2}{*}{$\begin{array}{l}\mathbf{N} \\
28\end{array}$} & \multirow{2}{*}{$\begin{array}{c}\begin{array}{c}\text { Pearson } \\
\text { Correlation }\end{array} \\
.750 * *\end{array}$} & \multirow{2}{*}{$\begin{array}{c}\begin{array}{c}\text { Sig. } \\
\text { (2-tailed) }\end{array} \\
.000\end{array}$} & \multirow{2}{*}{$\begin{array}{c}\begin{array}{c}\text { Sig. } \\
\text { Level }\end{array} \\
0.01\end{array}$} \\
\hline Gender & Male & & & & \\
\hline & female & 32 & $.783 * *$ & .000 & 0.01 \\
\hline \multirow{3}{*}{ Age } & $<30$ & 17 & $.612 * *$ & .016 & 0.01 \\
\hline & $30-40$ & 21 & $.611 * *$ & .003 & 0.01 \\
\hline & $>40$ & 22 & $.576^{*}$ & .002 & 0.05 \\
\hline \multirow[t]{2}{*}{ Area of residence } & Urban & 30 & .810 & .000 & 0.01 \\
\hline & rural & 30 & $.327^{*}$ & .003 & 0.05 \\
\hline \multirow[t]{2}{*}{ Educational status } & literate & 28 & $.641 * *$ & .000 & 0.01 \\
\hline & Illiterate & 32 & $.282 *$ & 0.005 & 0.05 \\
\hline \multirow[t]{2}{*}{ Marital status } & Married & 38 & $.633 * *$ & .000 & 0.01 \\
\hline & Unmarried & 32 & $.451 *$ & .000 & 0.05 \\
\hline \multirow[t]{3}{*}{ Duration of illness } & $<2 \mathrm{yrs}$ & 24 & $.703 * *$ & 0.012 & 0.01 \\
\hline & $2-5 \mathrm{yrs}$ & 19 & $.229 *$ & .345 & 0.05 \\
\hline & $>5 y r s$ & 17 & $.201 *$ & .358 & 0.05 \\
\hline
\end{tabular}

In both males and females the correlation between insight and depression is strong, as given by the Pearson coefficient more than 0.7 with significance at 0.01 levels (Table 7). The influence of age of patient on the correlation was also well established. In the group with age less than 30 yrs Pearson coefficient is 0.612 at a 0.01 significance level, whereas in other age group with age more than 40 years Pearson coefficient is 0.576 at a 0.05 significance level. The residents of urban area have more correlation than rural residents with Pearson coefficients.

Educational status of patient also shown its influence (Table 7), literates had more correlation than illiterates with Pearson coefficients of 0.641 and 0.282 and were significant at 0.01 and 0.05 respectively. Patients who were married have a strong correlation than unmarried with Pearson coefficients of 0.633 and 0.451 and were significant at 0.01 and 0.05 respectively. Patients in the early stages of illness had more correlation than at later stages, as evidenced by Pearson coefficients of $0.703,0.229,0.201 \mathrm{in}<2 \mathrm{yrs}, 2-5 \mathrm{yrs}$ and $>5 \mathrm{yrs}$ duration of illness groups respectively (Table 7).

\section{Discussion}

Poor insight was sometimes seen as just another symptom or manifestation of the disorder [15]. However, main conceptualisation was that poor insight represents an individual response to the diagnosis of schizophrenia and it has a relation to suicidal ideation [16]. Studies led to the hypothesis that there was a chain of causality from insight, to demoralisation, to depression, to suicidality [11]. In our study there was a strong correlation between insight and depression in schizophrenic population with a Pearson coefficient of 0.758. Our study results were in accordance with previous studies, which suggest that better insight is directly related to greater distress $[9,10,11,16]$. In a study done by Rocca et al, [17] male gender was associated with an increased severity of depressive symptoms. In contrary to above study, our results doesn't document any difference in the two genders in strength of correlation as both have $>0.7$ Pearson coefficient. In our study people residing in urban areas had stronger correlation than those in rural areas, explicable by more literacy rate, more exposure and more deficit awareness of the schizophrenic illness. The distress associated with "deficit awareness" was due to the insight of the practical constraints brought about by these deficits.

Previous studies reported that depressive symptoms are less frequent in schizophrenia patients in the chronic period than in the acute period [18, 19]. Studies on first episode psychosis had shown comparable higher levels 
of insight at the onset of illness (60\%). A higher insight during the baseline assessment in a first episode psychosis patient was positively correlated with a higher prevalence of depressive symptoms at this time [20]. A higher degree of insight predicts a higher risk for a subsequent post-psychotic depression and a higher risk of suicide during the first four years after receiving the diagnosis of psychosis [21]. Approximately $11 \%$ of the first episode psychosis patients, present self-harm episodes prior to their first diagnosis with an increased risk associated to male gender, low social class, depression, a longer Duration of Untreated Psychosis (DUP) and increased insight [22].

In our study also, the results were suggestive of more correlation as well as higher mean values of insight and depression in early stages of schizophrenic illness. As the duration of illness increases the insight about the illness diminishes and the rate of occurrence of depressive symptoms also falls down. Age of the patients also had shown similar trends, because most of the people experience the onset of schizophrenic illness when they are young.

In our study literate population had a stronger correlation than the illiterate population, explicable by more deficit awareness but this finding was in contrary to the study done by Amador et al, who documented that level of education and level of positive and negative symptoms of the illness were unrelated to insight, suggesting that deficits in illness awareness were not a consequence of educational background [23]. Current study had shown that married subjects had a lesser mean values of insight and depression than unmarried, but the correlation between insight and depression was strong in married subjects. This can be explained by the different coping mechanisms used by the patients of schizophrenia. Out of the two styles of coping, "Preference for positive reinterpretation and growth" coping style correlated with lower distress and with lower symptom awareness in married subjects who generally have a better social support. "Social supportseeking" coping style correlated with greater awareness of illness in unmarried schizophrenic subjects [24].

Limitations- Our study was a cross sectional study and the patients were not followed to measure the impact of insight. The results may not be applicable to a large scale population as the sample size was small. Treatment pattern of the patients and role of coping mechanisms were not considered.

\section{Conclusions}

Better insight was significantly correlated with lower mood. In addition, our study suggests that poor insight may protect against depression in the early stages of recovery from schizophrenia. The correlation between insight and depression was high in subjects with less duration of illness. There was a positive cross-sectional relationship between insight and depression, but the underlying processes need further clarification.

Funding: Nil, Conflict of interest: None initiated, Permission from IRB: Yes

\section{References}

1. Murray CJL, Salomon JA, Mathers CD). A critical examination of summary measures of population health. Bulletin of the World Health Organization, 2000;78: 981-994.

2. Rafael SE, Natalia OP, Arantzazu ZR, Jon GO, Javier PL, Uruchurtu IE e al. Insight in first episode psychosis. Conceptual and clinical consideration.

3. McGlashan TH, Carpenter WT Jr. Postpsychotic depression in schizophrenia. Arch Gen Psychiatry. 1976 Feb; 33(2):231-9.

4. Semrad EV: Long-term therapy of schizophrenia: formulation of the clinical approach, in Psychoneuroses and Schizophrenia. Edited by Usdin GP. Philadelphia, PA, JB Lippincott, 1966, pp 155-73.

5. Lincoln TM, Lüllmann E, Rief W. Correlates and long-term consequences of poor insight in patients with schizophrenia. A systematic review. Schizophr Bull. 2007 Nov;33(6):1324-42. Epub 2007 Feb 8.

6. Dickerson FB, Sommerville J, Origoni AE, Ringel NB, Parente F. Experiences of stigma among outpatients with schizophrenia. Schizophr Bull. 2002; 28(1):143-55.

7. Angermeyer MC, Matschinger $\mathrm{H}$, Corrigan $\mathrm{PW}$. Familiarity with mental illness and social distance from people with schizophrenia and major depression: testing a model using data from a representative population survey. Schizophr. Res. 2004;69(2-3):175-82.

8. Mulholland C, Cooper S. The symptom of depression in schizophrenia and its management. Adv. Psychiatr. Treat. 2000;6:169-77. 
9. Mintz AR, Dobson KS, Romney DM. Insight in schizophrenia: a meta-analysis. Schizophr Res. 2003 May 1;61(1):75-88.

10. Carroll A, Pantelis C, Harvey C. Insight and hopelessness in forensic patients with schizophrenia. Aust N Z J Psychiatry. 2004 Mar;38(3):169-73.

11. Schwartz RC, Smith SD. Suicidality and psychosis: the predictive potential of symptomatology and insight into illness. J Psychiatr Res.2004Mar-Apr;38(2):185-91.

12. Amador XF, Friedman JH, Kasapis C, Yale SA, Flaum M, Gorman JM. Suicidal behavior in schizophrenia and its relationship to awareness of illness. Am J Psychiatry. 1996 Sep;153(9):1185-8.

13. Moore O, Cassidy E, Carr A, O'Callaghan E. Unawareness of illness and its relationship with depression and self-deception in schizophrenia: European Psychiatry, Volume 14, Issue 5, p 264-9.

14. Macpherson R, Jerrom B, Hughes A. Relationship between insight, educational background and cognition in schizophrenia. Br J Psychiatry. 1996 Jun; 168 (6): 718-22.

15. Cuesta MJ, Peralta V. Lack of insight in schizophrenia. Schizophr Bull. 1994;20(2):359-66.

16. Cunningham Owens DG, Carroll A, Fattah S, Clyde Z, Coffey I, Johnstone EC. A randomized, controlled trial of a brief interventional package for schizophrenic out-patients. Acta Psychiatr Scand. 2001 May; 103 (5):362-9.

17. Rocca P, Bellino S, Calvarese P, Marchiaro L, Patria L, Rasetti R, Bogetto F. Depressive and negative symptoms in schizophrenia: different effects on clinical features. Compr Psychiatry.2005 Jul-Aug;46(4):304-10.
18. Bandelow B, Müller P, Gaebel W, Köpcke W, Linden M, Müller-Spahn F, Pietzcker A, Reischies FM, Tegeler J. Depressive syndromes in schizophrenic patients after discharge from hospital. ANI Study Group Berlin, Düsseldorf, Göttingen, Munich. Eur Arch Psychiatry Clin Neurosci. 1990;240(2):113-20.

19. Lancon C, Acquier P, Reine G, Barnard D, Addington D. Relationship between depression and psychotic symptoms of schizophrenia during an acute episode and stable period. Schizophr Res 2001; 47: 135-40.

20. Crumlish N, Whitty P, Kamali M, Clarke M, Browne S, McTigue O, et al. Early insight predicts depression and attemped suicide after 4 years in firstepisode schizophrenia and schizophreniform disorder. Acta Psychiatr Scand 2005; 112: 449-55.

21. Saeedi H, Addington J, Addington D. The association of insight with psychotic symptoms, depression, and cognition in early psychosis: a 3-year follow-up. Schizophr Res. 2007 Jan; 89 (1-3):123-8. Epub 2006 Nov 9.

22. Harvey SB, Dean K, Morgan C, Walsh E, Demjaha A, Dazzan P, Morgan K, Lloyd T, Fearon P, Jones PB, Murray RM. Self-harm in first-episode psychosis. Br J Psychiatry. 2008 Mar;192(3):178-84. doi: 10.1192/bjp. bp.107.037192.

23. Amador XF, Strauss DH, Yale SA, Flaum MM, Endicott J, Gorman JM. Assessment of insight in psychosis. Am J Psychiatry. 1993 Jun;150(6):873-9.

24. Michael C,Emmanuelle P, Dominic F, AnanthaPP, Anilkumar, Ingrid A, Elizabeth Kuipers, Veena Kumari. Insight, distress and coping styles in schizophrenia: Schizophr Res. 2007 Aug; 94(1-3): 12-22.

\section{How to cite this article?}

Ananda Reddy Endreddy, Subahani Shaik, Bhagawan Rajana. Schizophrenia - Insight, Depression: A correlation study. Int J Med Res Rev 2016;4(10):1820-1825.doi:10.17511/ijmrr. 2016.i10.18. 